\title{
Case study of a school wellbeing initiative: Using appreciative inquiry to support positive change
}

\author{
Lea Waters - Mathew White
}

\begin{abstract}
Drawing from the fields of positive psychology, positive organizational scholarship and educational administration, this case study reports on the process used in a large K-12 school to implement the strategic goal of fostering student wellbeing. This case study outlines the three strategic phases used to build wellbeing over a two-and-a-half-year time period: 1) development; 2) implementation; and 3) monitoring. The school aligned its change process to the goal of achieving wellbeing by adopting appreciative inquiry as the overarching change approach. Appreciative inquiry is a systematic, holistic, and collaborative methodology that follows a strengths-based model of change. Through the use of appreciative inquiry, 15 bottom-up (instigated by students and staff) and top-down (instigated by leadership) initiatives were generated over a two-and-a-half-year period. This paper provides an applied example of how AI can be woven into a strategic change process to support the wellbeing of students. The paper aims to contribute to the rapidly developing field of positive education.
\end{abstract}

Keywords: appreciative inquiry, positive psychology, positive organizational scholarship, educational administration, wellbeing

\section{Introduction}

Seligman and Csikszentmihalyi's (2000) foundational paper on positive psychology called for the promotion of "positive institutions" (p. 5), described as institutions that foster citizenship, virtue, and wellbeing. We argue that it is important for schools to be positive institutions that deliberately seek to foster citizenship, virtue, and wellbeing in today's students, especially given that these students are the forthcoming generation who will go on to shape our society (Clonan, Chafouleas, McDougal \& Riley-Tillman, 2004; Huebner, Gilman, Reschly \& Hall, 2009, p. 561). Successful examples abound of programs that foster citizenship, virtue, and wellbeing, coming from fields such as values education (Nielsen, 2005), character education (Berkowitz \& Bier, 2005), social-emotional learning (Durlak, Weissberg, Dymnicki, Taylor, \& Schellinger, 2011), and positive education (Seligman, Ernst, Gillham, Reivich, \& Linkins, 2009; Waters, 2011).

Rather than focus on a program, the current paper outlines a process used for creating positive school change designed to foster citizenship, virtue, and wellbeing in students. Specifically, this case study describes how the strategic goal of building wellbeing in students was supported using appreciative inquiry (AI) across three stages of change: (1) development; (2) implementation; and (3) monitoring.

Reynolds (2004) argued that successful school change is created when it is approached as both a top-down and bottom-up process; where the top-down processes provide strategic direction and goal setting whilst the bottom-up processes involve diagnosis and action. Copland (2003) adds to Reynolds' (2004) ideas about what creates successful change in schools and 
suggests "the use of an inquiry process is centrally important to building capacity for school improvement" (p. 375). This is because inquiry sets up norms that allow for continual change by empowering school members to inquire, identify, solve, and continually revisit change. In complement to the ideas above, many prominent writers in the field of school culture suggest that staff agency is a necessary condition for creating school change (Elmore, 2000; Fullan, 2001; Heck \& Hallinger, 2009). Finally, a growing number of researchers are also calling for the application of appreciative-based techniques to create cultural change in schools (Calabrese, Hester, Friesen, \& Burkhalter, 2010; Dickerson \& Helm-Stevens, 2011; Doveston \& Keenaghan, 2006; Willoughby \& Tosey, 2007). Hoy and Tarter (2011) argue that strengths-based approaches offer important new ways to assist schools to build administrative structures, processes, policies, and practices that enable a positive institution.

The current paper presents a case study of a K-12 school that established a new strategic goal to build wellbeing in students. Three stages of change used by the school in the current case study were underpinned by the four ideas described above. That is, the school adopted an approach to change that was: (1) collaborative and whole-school (both top-down and bottomup); (2) inquiry-based (asking rather than telling); (3) empowering (giving the organization's members the authority to create change rather than have change imposed upon them); and (4) appreciative (focused on building strengths as opposed to a focus on fixing weaknesses). These four principles were enacted through the adoption of appreciative inquiry as an overarching method to guide the strategic wellbeing initiative.

\section{What is appreciative inquiry and how does it work?}

$\mathrm{AI}$ is a relatively new change approach that meets the four criteria for successful school change enumerated above. AI is a systematic, holistic, and collaborative methodology that follows a strengths-based model of change in order to uncover the positive core of an organization (Cooperrider \& Whitney, 2005; Filleul \& Rowland, 2006). It differs from many other organizational change initiatives in that it creates large-scale change by harnessing the power of collective positive emotions, organizational strengths, and the relationships of the organization's members. In AI, people from all levels of an organization become part of an inquiry process that seeks to find the strengths in a system and to use those strengths as a platform to create change. Staff are empowered and given agency to plan, make decisions, and take action in the change process by inquiring appreciatively into what gives life to their workplace, what works best, and what is possible. According to Cooperrider and Whitney (2005), this approach is radically different to the more typical organizational development approaches to creating strategic change, which follow a deficit-based approach of diagnosing problems and errors in an organization and seek to create change by fixing these errors.

One of the most common appreciative inquiry approaches is the 4-D cycle, which is anchored in a positive topic of inquiry: Discovery, Dream, Design, and Destiny (Barrett \& Fry, 2005). The cycle is used to engage all of an organization's members by systematically inquiring into strengths, successes, positive stories, resources, and capabilities. The discovery stage asks 'What gives life?' and is designed to assist the organization's members to discover the positive elements that already occur in the organization. Appreciation of the positive in the organization builds confidence for successful future change. The dream stage asks participants to imagine 'What might be?' and create a positive image of the future. The design stage prompts participants to think of ways the dream can be enacted and take shape. The destiny/deliver stage aims to create the urge in organizational members to take personal responsibility for change. The team 
discusses co-operative ways to distribute the work to achieve the dream (Cooperrider \& Whitney, 2005) ${ }^{1}$.

The 4-D cycle can be used in a summit format, in one-on-one appreciative interviewing and can also be used as an ongoing change process in longer-term organizational change initiatives. For example, following on from the AI Summit, the 4-D cycle can be brought into classroom practice as a way to create change with students. It can be used by teachers to design projects and it can be used in staff task forces and committees (Cooperrider \& Whitney, 2005). Aside from the formal process of a 4-D cycle, AI also offers a guiding philosophy for leaders to support change initiatives. Even when a 4-D cycle is not used, leaders can still seek to support change through inquiry and collaboration to find the strengths that can be built upon to create ongoing change (Cooperrider \& Whitney, 2005).

The theory of positive organizational change, presented by Cooperrider and Sekerka (2003) and refined by Cooperrider (Cooperrider, 2012), suggests that AI fosters organizational change in three ways: (1) by elevating and extending the topic of inquiry; (2) by creating a broadening and building effect; and (3) by establishing strengths (relationships, resources, and ideas) that 'eclipse' the organization's problems. In elevation of inquiry, the organization's members are encouraged to widen their focus on and understanding of their work setting to see more of what is possible. The co-inquiry process into what is good about an organization creates amplified positive emotions in the AI participants, which then broadens their thinking and enhances their creativity regarding possible change initiatives. It also creates a sense of collective self-efficacy and builds up mutual regard, leading to increased social capital. The newfound relatedness combined with the clarity of strengths helps to activate collective energy, which creates a positive effect that spreads across the organization.

Although AI has grown in popularity, it is not free of criticism. One common concern is that the positive focus of AI may serve to invalidate or keep hidden the negative experiences of participants (Oliver, 2005) and can lead to one-sided, or half-formed, views of the organization (Bushe, 2011). However, others argue that the setting of a positive focus does not exclude the discussion of problems and that the dreams presented are often a reflection of the frustrations that come from unrealized potential and from barriers in the organization and consequently the negative aspects of an organization often arise during AI discussions (Bushe, 2011; Patton, 2003).

\section{The Case Study}

The case study site was a K-12 private boys' school in Australia. It is a non-selective school that is aligned to Episcopalian values. The school has 1,239 students and 151 staff (49\% female and $51 \%$ male; $60 \%$ teachers and $40 \%$ non-teaching roles such as administrative staff, information technology staff, grounds staff, catering staff). The school was founded in 1847 and hosts both day and boarding students.

In 2011 the school established a new three-year strategic plan that explicitly stated a goal to build a dynamic and comprehensive wellbeing program for its students. This was the first time in the school's history that wellbeing was an explicitly stated strategic goal. Specifically, the school's strategic goal for wellbeing was to create "an inspiring social and emotional learning environment where boys thrive" (St Peter's College, 2011, p. 8). The strategic plan states, "wellbeing is central to the development of our boys. We believe it is essential that boys

${ }^{1}$ For a more detailed explanation of the 4-D cycle, see Bushe, G. R. (2011). Appreciative inquiry: Theory and critique. In D. Boje, B. Burnes \& J. Hassard (Eds.), The Routledge companion to organisational change (pp. 87-103). Oxford, UK: Routledge. 
understand their wellbeing, and that of others; in the same way they read books, study mathematics, play in an orchestra or kick a football...we must equip our boys with capabilities that will enable them to develop lifelong resilience and understand how to use their strengths of character" (St Peter's College, 2011, p. 8).

The Senior Leadership Team (SLT), in consultation with the Council of Governors, decided to adopt AI as the guiding approach to develop, implement, and monitor the wellbeing strategy. AI was chosen over other potential change approaches for six important reasons: (1) the inclusive nature of AI meant that the leadership team was able to use this approach to gain valuable insights and knowledge from all staff about the factors that contribute to (or detract from) the boys' wellbeing. Given that it is staff who are at the 'chalk-face' with the boys, they add important, ground-level, information about the specific contexts and needs of the boys in this school; (2) the fact that a one-day AI Summit was a successful way of harnessing ideas from a large body of staff in a systematic and time-efficient manner; (3) a recognition that AI was likely to enhance staff buy-in to the new wellbeing initiatives because under AI staff are empowered to be active members in the change process itself and in the development of wellbeing practices; (4) a recognition that, given the newness of this goal within the school's more than 160-year history, the school would be better placed to devise a broad wellbeing goal and then allow room for initiatives to emerge over time through ongoing inquiry and collaboration (i.e., AI). This would provide time for staff and students to become more comfortable with the wellbeing culture rather than introducing a fully-devised wellbeing plan, which might be experienced as a 'culture shock'; (5) a belief by the SLT that using AI to encourage staff to participate in building a wellbeing culture for students would also indirectly build the wellbeing of staff through the experience of collaboration and through experiencing a strength-based change process; and finally, (6) leadership's commitment to setting a positive, future-oriented goal of building wellbeing in the students rather than simply diminishing ill-being. AI was considered to be an appropriate method for achieving that goal because it focuses on creating change by identifying and amplifying the positives in students, staff, and the school rather than by reducing weaknesses, flaws, and limitations.

The school set up three key phases to achieve its new wellbeing goal: (1) development; (2) implementation; and (3) monitoring. The school wove an AI approach into each of the three key phases of the strategic initiative as shown in figure 1 below. The arrows in figure 1 indicate that aspects of development were still continuing in the implementation phase (e.g., new ideas to support wellbeing were being developed during the implementation phase of the original ideas from the AI Summit) and that aspects of the monitoring phase were being fed back to refine the way in which various wellbeing projects were implemented.

It is important to note that although AI provided the underpinning philosophy for the school to enact its new wellbeing goal it was not the only approach used and the SLT also engaged in more traditional change approaches such as top-down planning, trouble-shooting, and problem solving. The aim of this paper is not to prove that AI caused the wellbeing initiatives that occurred in the school but, rather, to provide an applied example of how AI can be woven into a strategic change process and in order to support the wellbeing goals of a school. 
Figure 1: Three key phases supporting the strategic goal of building student wellbeing

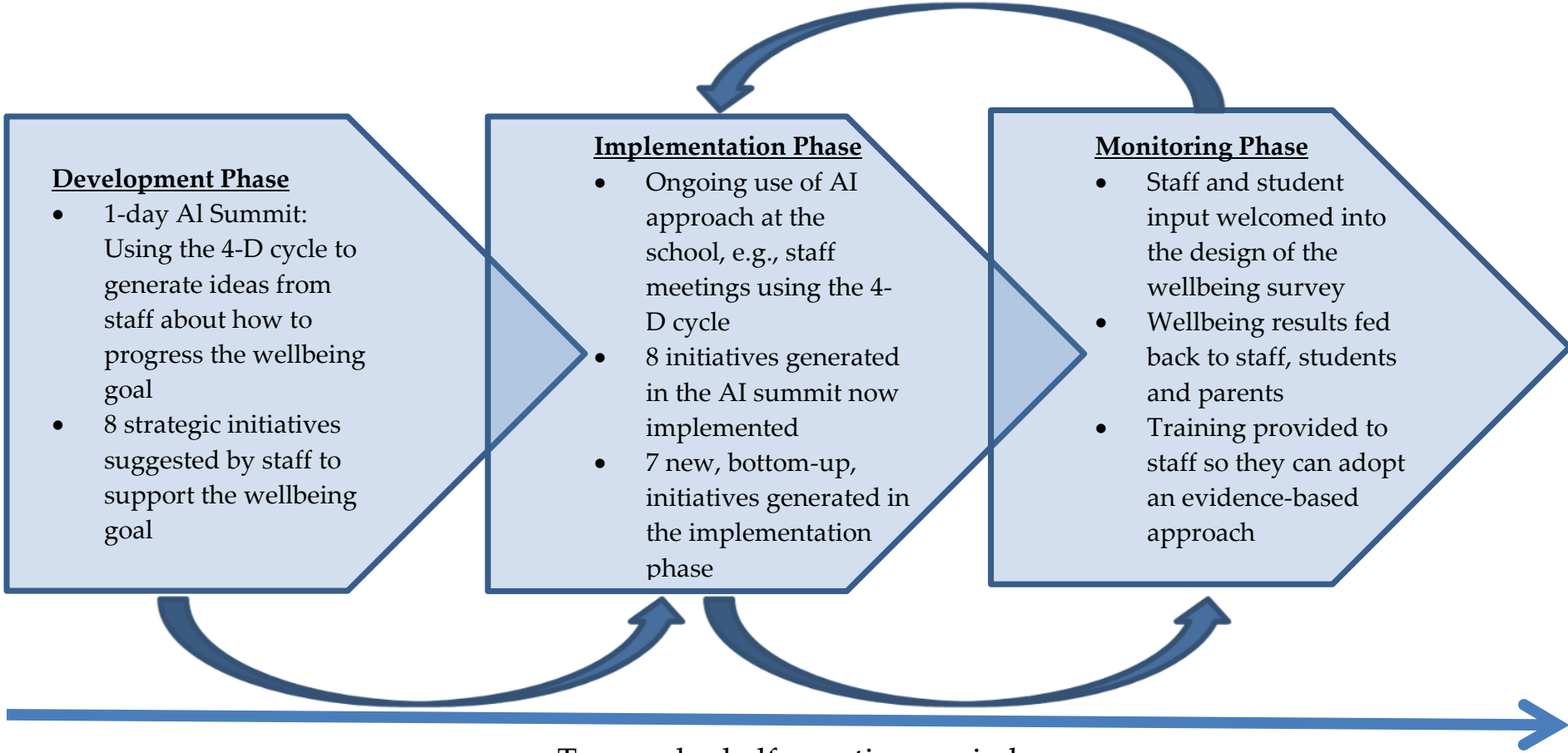

Two-and-a-half year time period

\subsection{Phase 1: Development}

The new strategic wellbeing goal was launched with a period of planning that was assisted by a one-day AI Summit, which was facilitated by the Head of Senior School. The affirmative topic for the summit was "Exceptional Wellbeing." Staff worked together for the full day on this affirmative topic. Staff were put into teams that were balanced for gender, sub-school, and staff classification to encourage collaboration across the different sub-schools and job roles. Teams then went through the 4-D cycle over the course of the day to explore what exceptional wellbeing looked like at the school and how more instances of exceptional wellbeing could be engendered.

In the discovery stage, participants were asked to pair up and share a time from the past where they had seen a student experience exceptional wellbeing at school. During the discovery stage they were encouraged to share their experience, first in pairs and then with the group just at their table. They then documented what they had shared and fed it back to the whole staff. Participants then moved into the dream stage and were asked to imagine their school at its best in five years' time. They used the strengths outlined in the discovery stories to consider what the school could look like if they had more of 'what is already working'. This stage was used to identify common themes that were used in the third stage, design, where the teams were asked to think about ways to actualize a wellbeing culture. Once the key design aspects had been identified, the groups moved onto the final stage, 'deliver', and were asked to think about concrete actions they could take to foster a culture of wellbeing.

Eight collective suggestions were made by the staff teams at the end of the AI Summit to support the school's strategic wellbeing goal: (1) the formation of a positive psychology interest group; (2) running parent information evening sessions and parent training courses on wellbeing; (3) discussing a boy's wellbeing explicitly in parent-teacher meetings in addition to discussing the boy's academic report card; (4) providing wellbeing activities for staff to boost staff wellbeing; (5) providing wellbeing training for staff so they can teach it to the boys; (6) developing a formal wellbeing curriculum for students; (7) measuring staff and student 
wellbeing; and (8) training to staff so they can adopt an evidence-based approach in their classes to assess the success of the wellbeing approaches in building the boys' wellbeing (this evidence sits outside the formal wellbeing survey administered to all boys).

After these suggestions were put forward by staff the SLT was able to then share with the staff that they had already discussed four of the actions that staff had suggested: running parent evenings, providing wellbeing training for staff, developing a formal wellbeing curriculum for students, and measuring wellbeing. However, through the AI Summit the staff had now given the SLT four new initiatives in support of the wellbeing goal: (1) the formation of a positive psychology interest group; (2) discussing a boy's wellbeing explicitly in parent-teacher meetings; (3) providing wellbeing activities for staff to boost staff wellbeing; and (4) training to staff so they could adopt an evidence-based approach in real-time in their classes to assess the success of wellbeing approaches in building the boys' wellbeing.

\subsection{Phase 2: Implementation}

During the implementation phase, the school leadership team were trained in the 4-D AI process by an external consultant. They then used this training in an ongoing action-reflection process to monitor the roll out of the school's wellbeing plan. The leadership team continued to ask appreciative questions when analyzing the school, such as: What are we doing well? What resources can we draw upon? What are our strengths and capabilities? How can we create ongoing motivation and commitment for change in staff? What is our dream for the future? The SLT welcomed further suggestions from school staff concerning how to build a wellbeing culture on an ongoing basis and encouraged the staff to continue to inquire and collaborate on the affirmative topic of building wellbeing.

Following the AI Summit, continued attention was placed on AI as a school-wide approach to build wellbeing. For example, teachers were encouraged to use AI in classrooms and AI in staff team meetings. A staff consultation group was also formed to continue to inquire and consult about the topic of wellbeing.

Two-and-a-half years after the launch of the strategic wellbeing goal, all eight suggestions raised in the Summit had been successfully implemented (see Table 1 below): (1) a positive psychology group of over 70 staff was formed, with representation from teaching, support staff, and grounds staff; (2) the school had run three parent evenings focusing on some of the skills taught to students in the wellbeing program; (3) at the first parent-teacher interview for the year in the Senior Years (ages 12-18 years) every student's mentor focused on a discussion of student wellbeing, character development and academic accomplishment; (4) the Physical Education Department volunteered to start a wellbeing club for staff, running weekly activities such as yoga, mindfulness, and Tai Chi; (5) the school engaged external training consultants to train all staff during a three-day wellbeing course; (6) all staff and students completed a wellbeing survey; (7) in 2013, the school introduced seven explicit wellbeing programs that have been embedded into the timetable at seven year levels - early learning centre (e.g., Kindergarden), Year 4, Year 5, Year 6, Year 7, Year 8, and Year 10 (the wellbeing curriculum reaches over 800 students in the school); and (8) the school engaged research experts to assist staff to use evidence-based techniques and collect on-going data in order to have evidence to track the progress of the learning and wellbeing initiatives ${ }^{2}$.

\footnotetext{
${ }^{2}$ Note: this initiative was suggested by staff in the planning stage and went on to form part of both the implementation phase and the monitoring phase.
} 
Table 1: Fifteen wellbeing initiatives implemented at the school over two-and-a-half years

Wellbeing initiatives suggested
by staff as a result of the AI
summit

The formation of a positive psychology interest group.

*Running parent information evening sessions and parent training courses on wellbeing.

Discussing boy's wellbeing explicitly in parent-teacher meetings in addition to boy's academic report card.

Providing wellbeing activities for staff to boost staff wellbeing.

*Providing wellbeing training for staff so they can teach it to the boys.

*Developing a formal wellbeing curriculum for students.

*Measuring student wellbeing.

Training to staff so they can adopt an evidence-based approach in real-time in their classes to assess the success of the wellbeing approaches in building the boys' wellbeing.

Summit suggested initiatives
enacted over a two-and-a-half-year
timeline

A positive psychology interest group was formed and over 70 staff joined the group with representation from teaching, support staff, and grounds staff. (2012)

The school had run three parent evenings focusing on some of the skills taught to students in the wellbeing program.

Teacher's now discuss a boy's VIA character strengths during parentteacher interviews.

The Physical Education Department volunteered to run a wellbeing club for staff and now runs weekly activities such as yoga, mindfulness, and Tai Chi.

The school engaged external training consultants to train all staff in a three-day wellbeing course. (2012)

The school introduced seven explicit wellbeing programs that have been embedded into the timetable at early learning - Year 4, Year 5, Year 6, Year 7, Year 8, and Year 10 (the wellbeing curriculum reaches over 800 students in the school).

Students (aged 13-18) completed a wellbeing survey (2011-2013).

A selection of teachers from the junior school, the senior school, education support officers, and all Heads of Departments and Faculty were trained by an external educational consulting company in evidence-based data collection processes. (2014)

\author{
Additional wellbeing initiatives \\ suggested by staff and enacted \\ post the AI summit \\ Teachers bringing positive \\ psychology into academic \\ curriculums such as English \\ Literature, Religion, and Drama. \\ (2012)
}

Sports coaches adopting positive psychology principles with students on the sports field. (2012)

Staff training the student captains in the AI methodology and the school captains using AI with school prefects.

(2013)

The student school captains hosting an AI Summit for student school leaders from other schools across Australia, which has now been run for three years in a row.

(2013)

AI questions were built into the recruitment, selection, orientation, and promotion policies and practices at the school.

(2013)

AI has now been integrated into policy and practice as one of the key methods to manage and create change and renewal through the St Peter's College Change and Renewal Framework developed by the culture and values committee at the School.

(2013)

Change to a more positively oriented behavior management policy.

(2013)

* Initiatives that were put forward by staff at the AI Summit that had already been identified as action steps by the senior leadership team. 
Admittedly, four of the initiatives outlined here (completing a wellbeing survey, introducing an explicit wellbeing curriculum, wellbeing training for teachers, and running parent education) were part of the SLT's initial plan to support the wellbeing goal and would have occurred even without taking an AI approach. However, leadership reported that because these four ideas were also generated by staff during the AI summit they were seen as 'shared ideas,' generated both by staff and leadership and, thus, had a high degree of buy-in. One positive example of this is the idea for parent education, which had originally been conceived by leadership who had planned to bring in an external consultant. However the idea was also suggested by staff in the AI Summit and ended up being run by three school staff with a team of ten teachers, who had shown themselves through this change process to have knowledge and passion for wellbeing, as facilitators.

The implementation phase also consisted of four new initiatives that came out of the AI Summit itself and that had not been pre-planned by the SLT: the formation of a positive psychology interest group, providing wellbeing activities for staff, discussing a boy's wellbeing explicitly in parent-teacher meetings in addition to the boy's academic report card, and training for staff so they could adopt an evidence-based approach. The first two of these initiatives were led by staff over the next 18 months as bottom-up/staff-organized initiatives. The second two ideas were generated by staff and were then aided by support from the SLT (e.g., the SLT provided a budget and hired an external company to train staff in evidence-based practice).

In addition to implementing the suggestions raised in the AI Summit/planning phase, seven new initiatives were suggested by school staff during the implementation phase over the ensuing two and half years: (1) Teachers bringing positive psychology into academic curriculums such as English Literature, Religion, and Drama; (2) sports coaches adopting positive psychology principles with students on the sports field; (3) staff training the two school captains in the AI methodology and the school captains using AI with school prefects; (4) the two school captains hosting an AI Summit for school leaders in other schools across Australia, an initiative which has now been run for three years in a row; (5) AI questions were built into the recruitment, selection, orientation, and promotion policies and practices at the school; (6) AI has now been integrated into the St Peter's College Change and Renewal Framework developed by the culture and values committee at the school; and (7) the school's behavior management policy was revised from being a punitive, de-merit model to focus more on positive behavioural and relational actions. The school introduced a systematic merit policy using an online database and developed processes where students were praised for good behaviour aligned with the school's values. This information was sent electronically to the student, mentor, and parents, which has enabled the school to map a student's behaviour, relations, effort, organisation, cooperation, and tenacity in any area of school life over a year.

All seven of these changes were bottom-up initiatives suggested by staff as part of the ongoing collaborative, inquiry-based AI approach, rather than changes that the senior leadership team had pre-determined. All staff were encouraged to continually come up with new ideas to build on strengths in the school to support the wellbeing goal.

Table 1 shows the wellbeing initiatives implemented at the school through the development and implementation phase over two-and-a-half years.

\subsection{Phase 3: Monitoring}

Copland (2003) suggests that using an inquiry-based process sets up norms that allow for continual change by empowering school members to inquire, identify, solve, and continually revisit the wellbeing goal. The AI tenets of collaboration, inquiry, empowerment, and 
appreciation were deliberately used in the monitoring phase. In the development phase both the SLT and the school staff had identified that in order to support the new strategic goal of boosting wellbeing, the school must start to measure student wellbeing alongside the traditional academic measures used. The motto of the first author of this paper is 'If you treasure it, you must measure it'.

Three key areas that have been monitored through evidence are: 1) the use of classroom practice to boost visible student wellbeing; 2) the use of the new behavior management systems and 3) the wellbeing of staff and students.

The use of classroom practice to boost signs of student wellbeing was monitored at the classroom level by teachers who had undertaken training in 2014 in evidence-based data collection processes. The training was provided by an external educational consulting company. The training was undertaken by 49 teachers in the junior school, 89 teachers in the senior school, 89 education support officers and all Heads of Department. The training equipped staff with the research tools to examine, on a regular basis, the effectiveness that their teaching was having on learning and wellbeing in their students. The data were used by these teachers to suggest new wellbeing initiatives to support the strategic wellbeing goal.

Evidence was also gathered about the use of the new behavior management systems. The school now collects data both for misbehavior (de-merits/red inks) and positive behavior (merits). In 2013, 4346 red inks were recorded and 4752 merits were recorded. In 2014, the red inks dropped slightly to 3724 and the merits rose substantially to 8722 merits. In fact, between 2013 and 2104, the number of merits almost doubled. The results show that teachers are now more likely than in previous years to focus on and record what students are doing right.

The final area that has been monitored by the school is the wellbeing of students and staff as assessed through a formal, biennial, on-line survey process. In 2011, the school worked with three university researchers ${ }^{3}$ to develop a comprehensive student wellbeing survey. The survey was designed to capture elements of PERMA (positive emotions, engagement, relationships, meaning, and accomplishment) (Seligman, 2011) and other elements of wellbeing such as life satisfaction and physical vitality. Once the pilot survey had been developed it was sent to staff for a consultation process. Staff suggestions were incorporated into the wellbeing survey. The survey was then shown to a group of senior student leaders who also added input to the survey. Finally, the survey was piloted with a group of students.

The survey was administered to 516 students (aged 13-18) at the end of the school year in $2011^{4}$. In the spirit of collaboration, inquiry, and empowerment, the results were fed back to all staff, senior students, and parents. The results were explored by staff as useful data to: (1) monitor the degree to which existing wellbeing approaches were working across different year levels; and (2) inform areas for future wellbeing directions.

At the end of the school year in 2013, the survey was re-administered to 709 students (aged 13-18) $)^{5}$. At the start of 2013 the school had introduced seven explicit wellbeing programs embedded into the timetable. In the survey at the end of 2013 participants were asked to think back over the past year and rate whether their knowledge and understanding of wellbeing and virtues had changed. Table 2 below shows the percentage of students who rated the survey

\footnotetext{
${ }^{3}$ Professor Lea Waters, University of Melbourne; Dr Margaret Kern, University of Pennsylvania and University of Melbourne; Mr Alejandro Adler, PhD candidate at University of Pennsylvania.

${ }^{4}$ For the wellbeing results of this survey and more detail about the development and implementation of the survey see Kern, Waters, Adler, \& White (2014).

5 The 2013 survey was designed and administered by Dr Peggy Kern, University of Pennsylvania and The University of Melbourne.
} 
questions as agree or strongly agree. The items assessing the students' self-reports of knowledge and understanding about wellbeing and strengths in self and others were high (all items were $80 \%$ and above). Interestingly, the two items that assessed behavior or more manifest, tangible outcomes such as being a good student and being a good friend, scored at $50 \%$ and $48 \%$ respectively. These results suggest that following the first year of the wellbeing curriculum, students are reporting that their knowledge about wellbeing is changing but this may not yet be leading to observable changes in other behaviors, such as study skills and social skills.

Table 2: Student responses to survey following wellbeing curriculum

\begin{tabular}{lc}
\hline Survey question & $\begin{array}{c}\text { \% who agreed or } \\
\text { strongly agreed }\end{array}$ \\
\hline $\begin{array}{l}\text { I have a better knowledge and understanding of my own wellbeing and } \\
\text { resilience. }\end{array}$ & $83 \%$ \\
I have a better understanding of the significance of my own strengths. & $83 \%$ \\
Positive education skills have helped me to become a better student. & $50 \%$ \\
I have a better understanding of my friends' wellbeing and resilience. & $82 \%$ \\
I have a better understanding of my friends' strengths. & $80 \%$ \\
Positive education skills have helped me to have better relationships & $48 \%$ \\
with my friends. & \\
\hline
\end{tabular}

\section{Discussion}

Schools have an important responsibility to be 'positive institutions' in our society. The current paper presents a case study of a three-phase change process designed to support the strategic goal of creating "an inspiring social and emotional learning environment where boys thrive" ( $\mathrm{p}$. 8 ), in a large K-12 school.

To support this strategic goal, the senior leadership team adopted a change process that was: (1) collaborative and whole-school and both top-down and bottom-up; (2) inquiry-based (asking rather than telling); (3) empowering (giving the organization's members the authority to create change rather than have change imposed upon them); and (4) appreciative (focused on strengths as opposed to a focus on fixing weaknesses). The AI approach was adopted following Cooperrider's (2012) idea that AI "combines enterprise-wide strengths for advancing strategic opportunities"' (p. 106).

A core tenet of AI is that the change process itself is inquiry-based and collaborative. AI was adopted in this school to foster a collaborative change process so that all the organization's members from all levels across the school could assist in the planning, implementation, and monitoring of the wellbeing goal. This inclusive approach served to promote new connections and relationships across the school. Dickerson and Helm-Stevens (2011) argue that top-down change efforts in schools are often unsuccessful because they "bump up against a school culture... of privacy and autonomy" (p. 67). In contrast, AI creates shifts in the social groupings that break down the silo mentality. We saw evidence for this in the current case study. For example, the positive psychology interest group brought together 70 people across the school who would not normally have much contact due to role differences and geographical separation. In addition, the training of all staff in wellbeing has broken down a division between teachers and counsellors because they are now working toward a common goal of boosting student wellbeing. These examples show that when members of an organization unite around an appreciative topic, it can serve to break down traditional barriers and create new networks. 
Another key aspect of $\mathrm{AI}$ is that it is a change process that identifies strengths within the organization and uses those strengths to support change. An example of this occurring in the current case study is the Physical Education Department launching a weekly staff wellbeing initiative following the AI Summit. Members of the Physical Education Department identified that their expertise in health and wellness was a strength they could share with staff to support wellbeing across the school. This department now has wide relationships with staff across the school. Another example involves members of the English Department who capitalized on their pedagogical expertise in teaching about character through novels and films to assist students to analyse their own character, together with fictional characters, using the positive psychology tool of the Values in Action (VIA) Character Strengths framework (Peterson \& Seligman, 2004; White \& Waters, 2014).

\section{Practical Implications}

This paper aims to be of practical value in other schools that seek to create positive cultural change. Our case study had a number of key learnings that can benefit other schools (or, indeed, other organizations) seeking to use an AI approach. First, the training of the SLT in AI was an important factor in enabling the school to adopt a continued AI approach over a two-and-a-halfyear time period because it allowed leadership to continue to communicate the themes of collaboration, inquiry, and strengths.

Second, the success of the AI Summit was contributed to by making it a whole-staff event and by designing the AI teams so that staff mixed with people across different areas of the school (e.g., a team might include staff from grounds and maintenance together with IT staff, catering staff, teachers, and middle managers). This approach allowed for full inclusion, the spread of ideas and blending of multiple perspectives. It also helped all staff, regardless of rank and role, to feel united in pursuing a positive goal, which energised them to enact the change initiatives generated for the design phase of the $\mathrm{AI}$ and to tap into different networks and groups across the school to build wellbeing (Waters, White, \& Murray, 2012).

Third, the AI Summit was run at a date in the school calendar where staff would be receptive and not overwhelmed with academic pressures. We suggest that organizations think about the timing of the AI Summit so that staff are most open and receptive to the 4-D process. For example, accounting firms would be unwise to run an AI Summit just prior to the end of the financial year. Likewise, retail companies should avoid an AI Summit immediately prior to sales seasons.

Fourth, careful planning went into the design of the use of AI at a 'macro-level' so that the AI philosophy could be infused in an ongoing way over the two-and-a-half years following the AI Summit in many aspects of the school, such as curriculum design, Human Resource policies, and co-curricula activities. The leadership team has encouraged staff to use the 4-D cycle in classrooms and across staff team projects and meetings in an ongoing way.

The introduction of AI has not come without challenges. First, some staff operated on the belief that decision-making is the role of senior leaders, and thus felt reluctant to contribute ideas about how to build wellbeing in the students. Second, other staff felt they lacked sufficient expertise in the topic of wellbeing to generate ideas, although the whole-staff wellbeing training helped to reduce this feeling over time. Third, some staff felt that the focus on strengths meant that challenges and barriers to wellbeing were not given sufficient consideration. Finally, change takes time to come to fruition: staff have been focusing on the use of appreciative processes to boost wellbeing in students but evidence as to the outcomes of change is still being accumulated. The early evidence is promising but more evidence is needed in the long term. 
AI places emphasis on collaborative methods that allow all members of an organization to contribute to change. The fact that nine of the 15 changes made over the two-and-a-half-year period were suggested and implemented by staff, rather than the SLT, is an indication that the collaborative nature of AI was embraced by the school. However, the vital role of the SLT cannot be underestimated. AI was combined with the top-down actions of the SLT, such as strategic planning, goal setting, making the decision to adopt an AI approach, resourcing the ideas put forward by staff and giving authority to staff to lead these ideas.

In conclusion, this case study provides one example that supports the growing number of calls in the field of educational leadership for schools to adopt more appreciative change approaches (Calabrese, 2006; Calabrese, Hummel, \& San Martin, 2007; Calabrese, San Martin, Glasgow, \& Friesen 2008).

\section{Authors}

Professor Lea Waters

University of Melbourne

l.waters@unimelb.edu.au

Dr. Mathew White

St Peter's College, South Australia

\section{Publishing Timeline}

Received 6 June 2014

Accepted 7 December 2014

Published 26 January 2015

\section{References}

Barrett, F., \& Fry, R. (2005). Appreciative inquiry: A positive approach to building cooperative capacity. Chagrin Falls, OH: Taos Institute Publications.

Berkowitz, M. W., \& Bier, M. C. (2005). Character education: Parents as partners. Educational Leadership, 63(1), 64-69.

Bushe, G. R. (2011) Appreciative inquiry: Theory and critique. In D. Boje, B. Burnes \& J. Hassard (Eds.), The Routledge companion to organisational change (pp. 87-103). Oxford, UK: Routledge.

Calabrese, R. (2006). Building social capital through the use of an appreciative inquiry: Theoretical perspective in a school and university partnership. International Journal of Educational Management, 20(3), 173-82. http://dx.doi.org/10.1108/09513540610654146

Calabrese, R., Hester, M., Friesen, S., \& Burkhalter, K. (2010). Using appreciative inquiry to create a sustainable rural school district and community. International Journal of Educational Management, 24(3), 250-265. http://dx.doi.org/10.1108/09513541011031592

Calabrese, R., Hummel, C., \& San Martin, T. (2007). Learning to appreciate at-risk students: Challenging the beliefs and attitudes of teachers and administrators. International Journal of Educational Management, 21(4), 275-291. http://dx.doi.org/10.1108/09513540710749500

Calabrese, R., San Martin, T., Glasgow, J., \& Friesen, S. (2008). The power of an appreciative inquiry 4-D cycle in a non-AYP middle school: Positive direction for eighth-grade teachers. Journal of Research for Educational Leaders, 4(2), 17-42.

Clonan, S. M., Chafouleas, S. M., McDougal, J. L., \& Riley-Tillman, T. C. (2004). Positive psychology goes to school: Are we there yet? Psychology in the Schools, 41(1), 101-110. http://dx.doi.org/10.1002/pits.10142

Cooperrider, D. (2012). The concentration effect of strengths: How the whole system "AI" summit brings out the best in human enterprise. Organisational Dynamics, 41, 106-117. 
Cooperrider, D., \& Sekerka, L. (2003). Elevation of inquiry into the appreciable world: Toward a theory of positive organisational change. In K. S. Cameron, J. E. Dutton, \& R. E. Quinn (Eds.), Positive organisational scholarship (pp. 3-13). San Francisco, CA: Berrett-Koehler.

Cooperrider, D. L., \& Whitney, D. (2005). Appreciative inquiry: A positive revolution in change. San Francisco: Berrett-Koehler.

Copland, M. (2003). Leadership of inquiry: Building and sustaining capacity for school improvement. Educational Evaluation and Policy Analysis, 25, 375-395. http://dx.doi.org/10.3102/01623737025004375

Dickerson, M. S., \& Helm-Stevens, R. (2011). Reculturing schools for greater impact: Using appreciative inquiry as a non-coercive change process. International Journal of Business and Management, 6(8), 66-74. http://dx.doi.org/10.5539/ijbm.v6n8p66

Doveston, M., \& Keenaghan, M. (2006). Growing talent for inclusion: Using an appreciative inquiry approach into investigating classroom dynamics. Journal of Research in Special Educational Needs, 6(3), 153-165. http://dx.doi.org/10.1111/j.1471-3802.2006.00073.x

Durlak, J. A., Weissberg, R. P., Dymnicki, A. B., Taylor, R. D., \& Schellinger, K. B. (2011). The impact of enhancing students' social and emotional learning: A meta-analysis of school-based universal interventions. Child Development, 82(1), 405-432. http://dx.doi.org/10.1111/j.1467-8624.2010.01564.x

Elmore, R. (2000). Building a new structure for school leadership. Washington, DC: The Albert Shanker Institute.

Filleul, M., \& Rowland, B. (2006). Using appreciative inquiry in the Vancouver school district: A positive approach to enhance learning. BC Educational Leadership Research, June, 1-10.

Fullan, M. (2001). Leading in a culture of change. San Francisco: Jossey-Bass.

Heck, R. H., \& Hallinger, P. (2009). Assessing the contribution of distributed leadership to school improvement and growth in math achievement. American Educational Research Journal, 46, 659-689. http://dx.doi.org/10.3102/0002831209340042

Hoy, W. K., \& Tarter, C. J. (2011). Positive psychology and educational administration: An optimistic research agenda. Educational Administration Quarterly, 47(3), 427-445.

http://dx.doi.org/10.1177/0013161X10396930

Huebner, E. S., Gilman, R., Reschly, A. L., \& Hall, R. (2009). Positive schools. In The Oxford handbook of positive psychology (pp. 561-569). Oxford: Oxford University Press.

Kern, M., Waters, L., Adler, A., \& White, M. (2014). A multifaceted approach to measuring wellbeing in students: Application of the PERMA framework. Journal of Positive Psychology, available as on-line first

Nielsen, T. W. (2005). Values education through thinking, feeling and doing. The Social Educator, 23(2), 3948.

Oliver, C. (2005). Critical appreciative inquiry as intervention in organisational discourse. In E. Peck (Ed.), Organisational development in healthcare: approaches, innovations, achievements (pp. 205-218). Oxford: Radcliffe Press.

Patton, M. Q. (2003). Inquiry into appreciative evaluation. In H. Preskill \& A. T. Coghlan (Eds.), Using appreciative inquiry in evaluation (pp. 85-99). San Francisco, CA: Jossey-Bass.

Peterson, C., \& Seligman, M. E. P. (2004). Character strengths and virtues: A handbook and classification. New York: Oxford University Press.

Reynolds, D (2004). School Effectiveness, School Improvement. London \& New York: Continuum International Publishing Group.

Seligman, M. E. P. (2011). Flourish. New York: Simon \& Schuster.

Seligman, M., \& Csikszentmihalyi, M. (2000). Positive psychology: An introduction. American Psychologist, 55(1), 5-14. http://dx.doi.org/10.1037/0003-066X.55.1.5

Seligman, M. E. P., Ernst, R. M., Gillham, J., Reivich, K., \& Linkins, M. (2009). Positive education: Positive psychology and classroom interventions. Oxford Review of Education, 35, 293-311. http://dx.doi.org/10.1080/03054980902934563

St Peter's College. (2011). Towards a preferred future: Strategic plan for St Peter's College 2011-2014. St Peter's College, Adelaide, Australia. Author

Waters, L. (2011). A review of school-based positive psychology interventions. Australian Educational and Developmental Psychologist, 28(2), 75-90. http://dx.doi.org/10.1375/aedp.28.2.75 
Waters, L., White, M., \& Murray, S. (2012). Toward the creation of a positive institution. The International Journal of Appreciative Inquiry, 14(2), 60-66.

White, M., \& Waters, L. (2014). The Good School: A case study of the use of Christopher Peterson's work to adopt a strengths-based approach in the classroom, chapel and sporting fields. Journal of Positive Psychology (on-line)

Willoughby, G., \& Tosey, P. (2007). Imagine 'Meadfield': Appreciative Inquiry as a process for leading school improvement. Educational Management Administration E Leadership, 35(4), 499-520.

http://dx.doi.rg/10.1177/174114320708105 